\title{
PENGARUH LOKASI DAN WAKTU PENGUKURAN SUMBER BERGERAK (KENDARAAN) DENGAN KANDUNGAN TIMBAL (Pb) PADA UDARA UNDERPASS DI SIMPANG LIMA MANDAI KOTA MAKASSAR Djoko Purwoko' dan Desi Enggar Prastiwi² \\ 1,2Jurusan Kesehatan Lingkungan Poltekkes Kemenkes Makassar desienggarprastiwi@gmail.com
}

\begin{abstract}
Lead $(\mathrm{Pb})$ is a heavy metal that is never found in pure form. Lead $(\mathrm{Pb})$ that pollutes the air namely in the form of particles. Timbal $(\mathrm{Pb})$ is largely produced by motor vehicle fumes and industry aluseofgasoline. The purpose of this research is to know the influence of location and time of moving source (Vehicle) with Lead content (Pb) on air underpass at Simpang Lima Mandai city of Makassar. This type of research is descriptive research by doing the measurement directly in the field. Pengkuran In the intersection of Five Mandai City of Makassar with the measurement time of morning and evening. The tools used in research are High Volume Sampler and Counter. And presented in tabular form. The result of Lead research (Pb) obtained result at point I Jl.Dakota at with

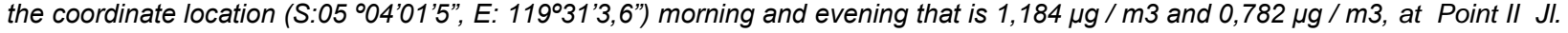
Sultan Hasanuddin Baru Airport with the coordinate location (S: 0504'04,9",E: $119^{\circ} 31^{\prime} 32,2^{\prime \prime}$ ) in the morning and afternoon is 0,562 $\mu \mathrm{g} / \mathrm{m} 3$ and $0.635 \mu \mathrm{g} / \mathrm{m3}$, and Point III Jl. Toll Engineer Sutami with the coordinate location (S: 0504'05,4" E: 19³1'28,7") in the morning and afternoon that is $0.617 \mu \mathrm{g} / \mathrm{m} 3$ and $0.251 \mu \mathrm{g} / \mathrm{m} 3$. From the results of research indicate that the highest Lead (Pb) content is at Coordinate Point Jalan Dakota Maros Makassar in the morning. The result of this research is in accordance with the attachment of South Sulawesi Governor's Regulation Number 69 Year 2010 regarding Quality Standard and Environmental Damage Criteria after testing for one hour measurement is $2 \mu \mathrm{g} / \mathrm{m} 3$. From the results of the study it is recommended that existing regulations regarding the restrictions on leaded gasoline and restrictions on the use of old vehicles in the application.
\end{abstract}

Keywords: Lead (Pb), Ambient Air, Underpass.

\section{ABSTRAK}

Timbal $(\mathrm{Pb})$ adalah logam berat yang tidak pernah ditemukan dalam bentuk murni. Timbal $(\mathrm{Pb})$ yang mencemari udara terdapat dalam partikel-partikel.Timbal $(\mathrm{Pb})$ sebagin besar dihasilkan oleh asap kendaraan bermotor dan industri yang menggunakan bensin. Tujuan penelitian ini mengetahui pengaruh lokasi dan waktu pengkuran sumber bergerak (Kendaraan) dengan kandungan Timbal $(\mathrm{Pb})$ pada udara underpass di Simpang Lima Mandai kota Makassar. Jenis penelitian ini merupakan penelitian deskriftif dengan melakukan pengukuran secara langsung di lapangan. Pengkuran Di simpang Lima Mandai Kota Makassar dengan waktu pengukuran pagi dan sore hari. Alat yang digunakan dalam penelitian yaitu High Volume Air Sampler dan Counter. Dan disajikan dalam bentuk tabel. Hasil penelitian Timbal $(\mathrm{Pb})$ diperoleh hasil pada Titik I JI.Dakota dengan Lokasi

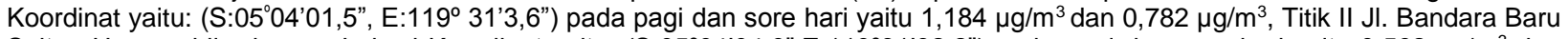

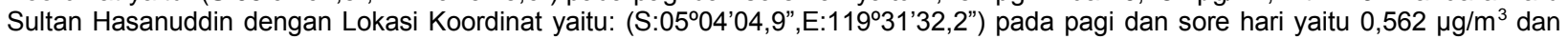
$0,635 \mu \mathrm{g} / \mathrm{m}^{3}$, dan Titik III JI. Tol Insinyur Sutami dengan Lokasi Koordinat yaitu: (S:0504'05,4"E:19³1'28,7") pada pagi dan sore hari yaitu $0,617 \mu \mathrm{g} / \mathrm{m}^{3}$ dan $0,251 \mu \mathrm{g} / \mathrm{m}^{3}$. Dari hasil penelitian menunjukkan bahwa kandungan Timbal $(\mathrm{Pb})$ tertinggi terdapat pada Titik Koordinat Jalan Dakota Maros Makassar pada pagi hari. Hasil penelitian tersebut sesuai dengan Lampiran Perturan Gubernur Sulawesi Selatan Nomor 69 Tahun 2010 Tentang Baku Mutu dan Kriteria Kerusakan Lingkungan setelah dilakukan pengujian selama satu jam pengukuran yaitu $2 \mu \mathrm{g} / \mathrm{m}^{3}$. Dari hasil penelitian disarankan agar peraturan yang ada menegnai pembatasan bensin bertimbal dan pembatasan penggunaan kendaraan yang sudah tua di terapkan.

Kata Kunci :Timbal $(\mathrm{Pb})$, Udara Ambien,Underpass

\section{PENDAHULUAN}

Pencemaran Udara merupakan suatu perubahan pada komposisi udara normal yang disebabkan oleh proses alami maupun kegiatan manusia, baik secara langsung maupun tidak langsung yang dapat menimbulkan akibat buruk pada makhluk hidup dan lingkungannya. Pencemaran udara merupakan pemasalahan yang sangat rumit, karena menyangkut hal-hal yang berkaitan dengan karakteristik fisik, sumber emisi zat pencemar.

Kemajuan teknologi dan pertambahan jumlah penduduk meningkatkan jumlah kendaraan bermotor dan kawasan industri di daerah perkotaan. Kegiatan pembakaran yang berlangsung tidak sempurna dari bahan bakar yang dipakai sebagai sumber energi bagi kendaraan bermotor terintroduksi ke udara dalam bentuk gas dan partikel. Gas buang kendaraan bermotor tersebut mengeluarkan bahan pencemar (polutan) yang berupa gas seperti

Karbon monoksida (CO), Timbal (Pb), Nitrogen oksida $\left(\mathrm{NO}_{\mathrm{x}}\right)$, Sulfur oksida $\left(\mathrm{SO}_{\mathrm{x}}\right)$, dan Hidrokarbon (HC) dan berupa seperti partikel debu, aerosol, timah hitam. Udara yang tercemar oleh polutan ini dapat menyebabkan gangguan pada kehidupan manusia, hewan dan tumbuhan. Gangguan kesehatan pada manusia dapat berupa iritasi, infeksi saluran pernapasan, gangguan pembentukan sel darah merah dan sebagainya (Moestikahadi, 2001).

Menurut Environment Project Agency, sekitar $25 \% \mathrm{~Pb}$ tetap berada dalam mesin dan $75 \%$ lainnya akan mencemari udara sebagai asap 
Jurnal Sulolipu : Media Komunikasi Sivitas Akademika dan Masyarakat

Vol. 17 No.II 2017

e-issn : 2622-6960, p-issn : 0854-624X

knalpot. Emisi $\mathrm{Pb}$ dari gas buangan tetap akan menimbulkan pencemaran udara dimanapun kendaraan itu berada, tahapannya adalah sebagai berikut: sebanyak $10 \%$ akan mencemari lokasi dalam radius kurang dari $100 \mathrm{~m}, 5 \%$ akan mencemari lokasi dalam radius $20 \mathrm{Km}$, dan $35 \%$ lainnya terbawa atmosfer dalam jarak yang cukup jauh.

Timbal $(\mathrm{Pb})$ yang berasal dari bensin berawal dari senyawa timbal organik, yaitu Ethyl Lead (TEL) dan Tetra Methyl (TML) dengan rumusan kimia masing-masing $\mathrm{Pb}\left(\mathrm{C}_{2} \mathrm{H}_{5}\right)$ dan $\mathrm{Pb}$ $\left(\mathrm{CH}_{3}\right)_{4}$ yang ditambahkan ke dalam bensin untuk meningkatkan bilangan oktan dan mencegah terjadinya letupan, sekitar $75 \%$ timbal dalam bensin diemisikan dalam bentuk partikal,sedangkan 25\% lainnya akan tetap berada dalam saringan asap kendaraan.

Perkembangan transportasi khususnya, transportasi didarat dari berbagai jenis kendaraan baik roda dua maupun roda empat pada umumnya menggunakan bahan bakar bensin premium. Kedalam premium ditambahkan timah hitam $(\mathrm{Pb})$ dalam bentuk timbal tetraetil dan tetrametil. Penambahan timbal ini meningkatkan bilangan oktan, agar titik bakarnya turun sehingga bensin lebih mudah terbakar. Dan emisinya akan membahayakan pada kesehatan manusia.

Menurut hasil pengamatan dan hasil survei pengamatan kondisi arus lalu lintas diperoleh gambaran volume dan komposisi lalu lintas kendaraan bermotor yang melintas pada ruas jalan Inspeksi Bandara dan ruas jalan Poros Bandara Baru pada tahun 2015 kondisi volume lalu lintas kedua ruas jalan pada hari libur dan hari kerja relatif sama dan cenderung tinggi pada saat di pagi hari kemudian menurun hingga petang hari, jam-jam puncak terjadi pada pagi hari dengan kondisi tertinggi terjadi rata-rata pada pukul 08.0009.00 WITA, jumlah volume kendaraan relatif lebih tinggi pada jalan Poros Bandara Baru diperoleh hasil rata-rata yaitu: 941,00 Volume Lalu Lintas (smp/jam), sedangkan pada ruas Jalan Inspeksi Bandara Pada pukul 08.00-09.00 WITA diperoleh hasil rata-rata yaitu: 296,60 Volume Lalu Lintas (smp/jam) (Dinas Lingkungan Hidup Kota Makassar ANDAL, 2015).

Diputuskan dibangunnya Jalan Underpass ini, karena pada persimpangan tak sebidang ini sering mengalami kemacetan panjang, yang mengindikasikan volume arus kendaraan yang semakin meningkat. Berdasarkan survei yang dilakukan, volume lalu lintas pada jam sibuk dari segala arah yang bertemu di persimpangan titik temu dari Kota Makassar ke arah Kabupaten Maros melalui Jl. Perintis Kemerdekaan dan Jalan Tol Seksi Empat, dan juga untuk akses menuju Bandara Internasional Sultan

Hasanuddin ini mencapai antara 9.500 hingga 10.000 Satuan Mobil Penumpang (smp) per jam. Masalah lain dibangunnya Jalan Underpass ini yaitu masih rendahnya tingkat kepatuhan pengendara roda dua pada kanalisasi yang telah ditetapkan. Padahal sejak dari oprit ke jalan samping, sudah dibuatkan kanalisasi sehingga Jalan Underpass ini menjadi langganan kemacetan setiap harinya yang disebabkan sempitnya ruas jalan samping kiri kanan di kawasan pengerjaan proyek.

Jalan-jalan utama di Kota Makassar sering padat kendaraan dan terjadinya kemacetan. Tentunya ini merupakan suatu kenyataan bahwa Kota Makassar memang Kota terbesar di kawasan Timur Indonesia dengan aktifitas penduduknya yang begitu sibuk untuk mencari kebutuhan dalam memenuhi kebutuhan hidupnya. Tingginya kepadatan kendaraan di suatu wilayah akan mengakibatkan tingginya pencemaran udara di daerah terutama Kadar Timbal $(\mathrm{Pb})$.

\section{BAHAN DAN METODE}

\section{Lokasi Penelitian}

Lokasi atau tempat Penelitian ini dilaksanakan Di Simpang Lima Mandai Kota Makassar (Maros,Makassar,Tol,Bandara). Pemilihan lokasi penelitian ini merupakan tempat yang dapat mewakili daerah jalur padat kendaraan khususnya di sepanjang jalan Bandara.

\section{Waktu Penelitian}

Peneltian ini dilakukan di tiga titik yang diambil dan di yakini dapat mewakili dari lokasi sepanjang jalan tersebut pada jalur yang lancar dan jalur macet kendaraan. Dan tiga titk tersebut dilakukan pengukuran sebanyak dua waktu masing-masing yaitu pagi hari dan sore hari. Waktu penelitian diambil pada pagi hari karena temperature udara relatif rendah, selain itu survey dilakukan pada pukul 08.00-09.00 WITA selama 60 menit, hal tersebut dikarenakan waktu di mulainya melakukan suatu aktivitas sehingga padatnya kendaraan. Kemudian dilanjutkan survey berikutnya dilakukan pada sore hari pada pukul 16.0017.00 WITA keadaan lalu lintas kembali padat karena para pengendara kembali dari semua aktivitas. 
Adapun tahap-tahap waktu yang di jadwalkan oleh penulis yakni dibagi atas tiga tahap :

a. Tahap persiapan bulan Januari-Februari 2017 Dalam hal ini,yakni observasi pendahuluan atau observasi lapangan dan pengambilan data-data sekunder untuk menyusun proposal penelitian.

b. Tahap pelaksanaan bulan April-Mei 2017 Dalam tahap ini,yaitu tahap untuk perbaikan dan menyelesaikan penyusunan skripsi.

c. Tahap penyelesaian bulan Juni-Juli 2017 Dalam tahap ini, yaitu tahap untuk perbaikan dan penyelesaian penyusunan skripsi.

\section{Variabel Penelitian}

\section{a. Variabel Bebas}

Variabel bebas adalah variabel yang diduga berpengaruh terhadap variabel terikat dalam hal ini meliputi: lokasi dan waktu pengukuran sumber bergerak (Kendaraan).

b. Variabel Terikat

Variabel terikat adalah variabel yang dipengaruhi oleh variabel bebas dalam hal ini adalah kandungan Timbal $(\mathrm{Pb})$ dalam udara ambien.

c. Variabel Pengganggu

Variabel Pengganggu adalah variabel yang turut berpengaruh terhadap variabel bebas,dan variabel terikat dalam hal ini adalah suhu,kelembaban udara,arah dan kecepatan angin,sinar matahari,hujan,pohon.

\section{Pengumpulan Data}

a. Data Primer

Data primer adalah data penelitian yang diperoleh dari hasil pemeriksaan kandungan Timbal $(\mathrm{Pb})$ pada udara ambien yang dilakukan pada dua pembagian waktu yang dihubungkan dengan kepadatan pada saat jam tertentu.

b. Data Sekunder

Data sekunder adalah data yang diperoleh dari hasil kepustakaan serta literatur-literatur yang ada hubungannya dengan objek penelitian,data dari Dinas Lingkungan Hidup Kota Makassar,Samsat,dan Kapolda (jumlah kendaraan di Kota Makassar), dan dari situs internet.

\section{Analisis Data}

Data yang diperoleh dari hasil pengukuran di lapangan diolah secara manual (rata-rata) kemudian disajikan dalam bentuk tabel dan di narasikan,kemudian dijelaskan secara deskriptif dengan menganalisa hasil pemeriksaan laboratorium dengan membandingkan hasil dari beberapa penelitian yang dapat digunakan sebagai literatur kemudian dihubungkan dengan faktor-faktor yang mempengaruhi Kandungan Timbal $(\mathrm{Pb})$ pada Udara ambien di Simpang Lima Mandai Kota Makassar, kemudian di kaitkan dengan peraturan yang di gunakan sebagai standar yang ada selanjutnya ditarik kesimpulan dan saran.

\section{HASIL PENELITIAN}

Adapun hasil penelitian ini yang telah dilakukan sebanyak 3 titik dan setiap titik pengambilan sampel yaitu pada pagi dan sore hari yaitu sebagai berikut:

1. Hasil Pengukuran Kandungan Logam Berat Timbal (Pb) pada tanggal 23 Mei 2017 pada Pagi dan Sore hari Di Jalan Mandai Kota Makassar.

Tabel 1

Hasil Pengukuran Kandungan Logam Berat Timbal (Pb) Tanggal 23 Mei 2017 Pada Pagi dan Sore Hari Di Jalan Mandai Kota Makassar

\begin{tabular}{|c|c|c|c|c|}
\hline $\begin{array}{l}\mathbf{N} \\
\mathbf{0}\end{array}$ & $\begin{array}{c}\text { TITIK } \\
\text { PENGUKUR } \\
\text { AN }\end{array}$ & $\begin{array}{c}\text { WAKTU } \\
\text { PENGUKUR } \\
\text { AN }\end{array}$ & LOKASI & $\begin{array}{l}\text { HASILTIM } \\
\text { BAL (Pb) } \\
\mu g / \mathrm{Nm}^{3}\end{array}$ \\
\hline 1 & $\begin{array}{l}\text { Titik I Jl. } \\
\text { Dakota } \\
\text { Maros- } \\
\text { Makassar }\end{array}$ & $\begin{array}{c}08.00-09.00 \\
\text { WITA }\end{array}$ & $\begin{array}{c}\text { S:0504'01,5" } \\
E: 119^{\circ} \\
31^{\prime} 3,6^{\prime \prime}\end{array}$ & $\begin{array}{l}1,184 \\
\mu g / m^{3}\end{array}$ \\
\hline & $\begin{array}{l}\text { Titik I J. } \\
\text { Dakota } \\
\text { Maros- } \\
\text { Makassar }\end{array}$ & $\begin{array}{c}16.00-17.00 \\
\text { WITA }\end{array}$ & $\begin{array}{l}\text { S:0504' } \\
01,5^{\prime \prime} \\
\text { E:119} \\
31^{\prime} 3,6^{\prime \prime}\end{array}$ & $\begin{array}{l}0,782 \\
\mu \mathrm{g} / \mathrm{m}^{3}\end{array}$ \\
\hline 2 & $\begin{array}{c}\text { Titik II Jl. } \\
\text { Bandara } \\
\text { Baru Sultan } \\
\text { Hasanuddin }\end{array}$ & $\begin{array}{c}08.00-09.00 \\
\text { WITA }\end{array}$ & $\begin{array}{c}\text { S: } \\
05^{\circ} 04^{\prime} 04,9^{\prime \prime} \\
\text { E:119³1'32, } \\
2^{\prime \prime}\end{array}$ & $\begin{array}{l}0,562 \\
\mu \mathrm{g} / \mathrm{m}^{3}\end{array}$ \\
\hline & $\begin{array}{c}\text { Titik II Jl. } \\
\text { Bandara } \\
\text { Baru Sultan } \\
\text { Hasanuddin }\end{array}$ & $\begin{array}{c}16.00-17.00 \\
\text { WITA }\end{array}$ & $\begin{array}{c}\mathrm{E}: 119^{\circ} 31^{\prime} 32, \\
2 "\end{array}$ & $\begin{array}{l}0,635 \\
\mu \mathrm{g} / \mathrm{m}^{3}\end{array}$ \\
\hline 3 & $\begin{array}{l}\text { Titik III } \\
\text { Jl.Tol } \\
\text { Insinyur } \\
\text { Sutami }\end{array}$ & $\begin{array}{c}08.00-09.00 \\
\text { WITA }\end{array}$ & $\begin{array}{l}\text { S:0504'05,4 } \\
" \\
E: 19^{\circ} 31^{\prime} 28,7\end{array}$ & $\begin{array}{c}0,617 \\
\mu g / m^{3}\end{array}$ \\
\hline & $\begin{array}{l}\text { Titik III } \\
\text { Jl.Tol } \\
\text { Insinyur } \\
\text { Sutami }\end{array}$ & $\begin{array}{c}16.00-17.00 \\
\text { WITA }\end{array}$ & $\mathrm{E}:{ }^{\circ}{ }^{\circ} 31^{\prime} 28,7$ & $\begin{array}{c}0,251 \\
\mu \mathrm{g} / \mathrm{m}^{3}\end{array}$ \\
\hline
\end{tabular}

Sumber: Data Primer, 2017 
Jurnal Sulolipu : Media Komunikasi Sivitas Akademika dan Masyarakat

Vol. 17 No.II 2017

e-issn : 2622-6960, p-issn : 0854-624X

Keterangan : Standar Baku Mutu Udara Untuk Timbal $(\mathrm{Pb})$ Yaitu $2 \mu \mathrm{g} / \mathrm{m}^{3}$. (PeraturanGubernur Sul-Sel Nomor 69 Tahun 2010)

2. Hasil Pengukuran Jumlah Sumber bergerak (Kendaraan) Yang Lewat Tanggal 23 Mei 2017 Pagi dan Sore Hari Di Jalan Mandai Kota Makassar

\section{Tabel 2}

Hasil Pengukuran Jumlah Sumber Bergerak (Kendaraan) Tanggal 23 Mei 2017 Pada Pagi dan Sore Hari Di Jalan Mandai Kota Makassar

\begin{tabular}{|c|c|c|}
\hline \multirow{2}{*}{$\begin{array}{l}\text { TITIK } \\
\text { PENGUKURAN }\end{array}$} & \multicolumn{2}{|c|}{$\begin{array}{l}\text { JUMLAH SUMBER } \\
\text { BERGERAK (KENDARAAN)/ } \\
\text { UNIT }\end{array}$} \\
\hline & PAGI & SORE \\
\hline $\begin{array}{l}\text { Titik I ال. Dakota } \\
\text { Maros (S: } \\
\text { 0504'01,5’, E: } \\
\left.119^{\circ} 31^{\prime} 3,6^{\prime \prime}\right)\end{array}$ & 2980 Unit & 2840 Unit \\
\hline $\begin{array}{l}\text { Titik II Jl. Bandara } \\
\text { Baru Sultan } \\
\text { Hasanuddin (S: } \\
05^{\circ} 04^{\prime} 04,9^{\prime \prime}, \text { E: } \\
1_{\left.119^{\circ} 31^{\prime} 32,2^{\prime \prime}\right)} \\
\end{array}$ & 2670 Unit & 2563 Unit \\
\hline $\begin{array}{l}\text { Titik III J. Tol } \\
\text { Insinyur Sutami, } \\
\text { (S: 0504'05,4', E: } \\
\text { 19³1'28,7') }\end{array}$ & 2730 Unit & 1776 Unit \\
\hline
\end{tabular}

3. Jumlah Sumber Bergerak (Kendaraan) dan Kandungan Timbal (Pb) Udara Pada Pengukuran Pagi Hari.

\section{Tabel 3}

Jumlah Sumber Bergerak (Kendaraan) dan Kandungan Timbal $(\mathrm{Pb})$ Udara Pada Pengukuran Pagi Hari Di Jalan Mandai Kota Makassar

\begin{tabular}{|c|c|c|}
\hline TITIK & PENGUKURAI & ADA PAGI HARI \\
\hline PENGUKURAN & $\begin{array}{l}\text { KANDUNGAN } \\
\text { TIMBAL (Pb) }\end{array}$ & $\begin{array}{c}\text { JUMLAH } \\
\text { SUMBER } \\
\text { BERGERAK } \\
\text { (KENDARAAN) }\end{array}$ \\
\hline $\begin{array}{l}\text { Titik I Jl. Dakota Maros } \\
\text { (S: } 05^{\circ} 04^{\prime} 01,5^{\prime \prime}, \mathrm{E}: 119^{\circ} \\
\left.31^{\prime} 3,6^{\prime \prime}\right)\end{array}$ & $1,184 \mu \mathrm{g} / \mathrm{Nm}^{3}$ & 2980 \\
\hline $\begin{array}{l}\text { Titik II Jl. Bandara Baru } \\
\text { Sultan Hasanuddin (S: } \\
05^{\circ} 04^{\prime} 04,9^{\prime \prime}, \text { E: } \\
\left.119^{\circ} 31^{\prime} 32,2^{\prime \prime}\right)\end{array}$ & $0,562 \mu \mathrm{g} / \mathrm{Nm}^{3}$ & 2670 \\
\hline $\begin{array}{l}\text { Titik III JI. Tol Insinyur } \\
\text { Sutami (S: } 05^{\circ} 04^{\prime} 05,4^{\prime \prime}, \\
\text { E: } 19^{\circ} 31^{\prime 28,7 ")}\end{array}$ & $0,617 \mu \mathrm{g} / \mathrm{Nm}^{3}$ & 2730 \\
\hline
\end{tabular}

4. Jumlah Sumber Bergerak (Kendaraan) dan Kandungan Timbal (Pb) Udara Pada Pengukuran Sore Hari.

Tabel 4

Jumlah Sumber Bergerak (Kendaraan) dan Kandungan Timbal $(\mathrm{Pb})$ Udara Pada Pengukuran Sore Hari Di Jalan Mandai Kota Makassar

\begin{tabular}{|c|c|c|}
\hline TITIK & \multicolumn{2}{|c|}{ PENGUKURAN PADA SORE HARI } \\
\hline PENGUKURAN & $\begin{array}{l}\text { KANDUNGAN } \\
\text { TIMBAL (Pb) }\end{array}$ & $\begin{array}{c}\text { JUMLAH SUMBER } \\
\text { BERGERAK } \\
\text { (KENDARAAN) }\end{array}$ \\
\hline $\begin{array}{c}\text { Titik I Jl. Dakota } \\
\text { Maros (S: } 05^{\circ} 04^{\prime} 01,5^{\prime \prime}, \\
\left.\text { E: } 119^{\circ} 31^{\prime} 3,6^{\prime \prime}\right)\end{array}$ & $0,782 \mu \mathrm{g} / \mathrm{m}^{3}$ & 2840 \\
\hline $\begin{array}{l}\text { Titik II Jl. Bandara } \\
\text { Baru Sultan } \\
\text { Hasanuddin, (S: } \\
\text { 0504'04,9", E: } \\
\text { 119॰31'32,2") }\end{array}$ & $0,635 \mu \mathrm{g} / \mathrm{m}^{3}$ & 2563 \\
\hline $\begin{array}{c}\text { Titik III Jl. Tol Insinyur } \\
\text { Sutami (S: } \\
05^{\circ} 04^{\prime} 05,4^{\prime \prime}, \mathrm{E}: \\
\left.19^{\circ} 31^{\prime} 28,7^{\prime \prime}\right)\end{array}$ & $0,251 \mu \mathrm{g} / \mathrm{m}^{3}$ & 1776 \\
\hline
\end{tabular}

\section{PEMBAHASAN}

1. Hasil Pengukuran Timbal (Pb) Di Jalan Mandai Kota Makasar.

Berdasarkan Tabel 5.1 diatas dapat diketahui bahwa dari 3 Titik pengukuran yang dilakukan Di Jalan Mandai Kota Makassar maka diperoleh hasil tertinggi yaitu pada pengukuran pagi hari di Titik I Di Jl.Dakota Maros-Makassar dengan Lokasi Koordinat yaitu: (S:0504'01,5' dan E:119 ${ }^{\circ} \quad 31^{\prime} 3,6^{\prime \prime}$ ) dengan Kandungan Timbal $(\mathrm{Pb})$ yaitu 1,184 $\mu \mathrm{g} / \mathrm{m}^{3}$ sedangkan hasil terendah diperoleh pada pengukuran sore hari di Titik III Di Jl. Tol Insinyur Sutami dengan Lokasi Koordinat yaitu: (S:05'04'05,4" dan E:19³1'28,7') dengan kandungan Timbal $(\mathrm{Pb})$ yaitu $0,251 \mu \mathrm{g} / \mathrm{m}^{3}$.

Berdasarkan hasil pengukuran Timbal $(\mathrm{Pb})$ diketahui bahwa dari 3 titik pengukuran yang dilakukan Di Jalan Mandai Kota Makassar maka diperoleh hasil tertinggi yaitu pada pengukuran pada pagi hari di Titik I Jalan Dakota Maros-Makassar dengan Lokasi

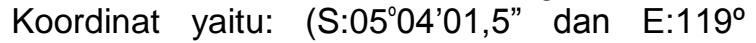
31'3,6") dengan Kandungan Timbal $(\mathrm{Pb})$ yaitu $1,184 \mu \mathrm{g} / \mathrm{m}^{3}$. Berarti diketahui bahwa semua Titik Pengukuran masih memenuhi syarat sesuai dengan Peraturan Gubernur Sul-Sel Nomor 69 Tahun 2010 Tentang Baku Mutu dan Kriteria Kerusakan Lingkungan Hidup, sesuai dengan Standar baku mutu udara ambien.

Menurut Environment Project Agency,sekitar 25\% Pb tetap berada dalam 
mesin dan $75 \%$ lainnya akan mencemari udara sebagai asap knalpot. Emisi Timbal $(\mathrm{Pb})$ dari gas buangan tetap akan menimbulkan pencemaran udara dimanapun kendaraan itu berada, tahapannya adalah sebanyak $10 \%$ akan mencemari lokasi dalam radius kurang dari 100 meter,dan $45 \%$ akan mencemari lokasi dalam radius $20 \mathrm{~km}$ dan $35 \%$ lainnya terbawa atmosfer dalam jarak yang cukup jauh.

Hal tersebut disebabkan karena adanya emisi sumber bergerak (Kendaraan) yang mengandung Timbal (Pb). Pencemaran Timbal yang disebabkan oleh penggunaan tetraetil- $\mathrm{Pb}$ dan tetrametil- $\mathrm{Pb}$ dalam bahan bakar berkualitas rendah untuk menurunkan nilai oktan sebagai anti-knock mesin kendaraan. Bahan aditif yang ditambahkan kedalam bahan bakar kendaraan pada umumnya terdiri dari $62 \%$ tetraetil-pb, $18 \%$ etilonklorida, $18 \%$ etillonbromida,dan $2 \%$ campuran bahan lainnya (Palar,2004).

Pada pengukuran pada pagi hari diperoleh hasil lebih tinggi kandungan Timbal (Pb) udara ambien di Jalan Mandai Kota Makassar dibandingkan dengan pengukuran pada sore hari,hal ini disebabkan oleh bensin premium dengan nilai oktan 87 mengandung 0,70-0,84 teraetil- $\mathrm{Pb}$ dan tetrametil- $\mathrm{Pb}$ sehingga menjadi sebesar $0,56-0,63 \mathrm{~g} \mathrm{~Pb}$ yang dilepaskan ke udara dari setiap liter bensin (Siregar dalam Isdaryanti,2011).

Kandungan logam berat Timbal $(\mathrm{Pb})$ sebagai gas buang pada sumber bergerak (Kendaraan) yang dapat membahayakan bagi kesehatan terutama pada sistem saraf pusat serta dapat menyebabkan keracunan akut dan merusak lingkungan. Logam berat Timbal (Pb) yang terhirup oleh manusia setiap hari akan diserap,disimpan dan kemudian ditampung dalam darah (Surani,2002).

Kandungan logam berat Timbal (Pb) pada udara ambien disekitar Jalan Mandai Kota Makassar yang paling tertinngi pada saat pengukuran yaitu $1,184 \mu \mathrm{g} / \mathrm{m}^{3}$. Hal ini disebabkan oleh peran pemerintah yang ada pada tahun 2000an sudah menghimbau Pertamina untuk menghapus zat aditif TEL secara bertahap. Dan dalam upaya mendukung adanya Program Langit Biru Indonesia yang tertuang dalam UU No.36/2009 tentang Kesehatan serta instruksi Menteri Lingkungan Hidup RI tahun 2000 yang berisi penghapusan bensin bertimbal secara bertahap di seluruh Indonesia,akhirnya Pertamina berhasil menunaikan misinya. Secara resmi per-1 juli 2006 penggunaan Timbal (TEL) sebagai Octan Booster atau zat aditif pengolah angka oktan terus ditekan hingga mencapai titik ideal aman Timbal (Iwan,2014).

Adapun hasil penelitian tertinggi pada saat pengukuran pada hari kerja menunjukkan bahwa Di Jalan Mandai Kota Makassar pada Titik I Di Jalan Dakota Maros-Makassar dengan Lokasi Koordinat yaitu: (S:05 $04^{\prime} 01,5^{\prime \prime}$ dan $\left.\mathrm{E}: 119^{\circ} 31^{\prime} 3,6^{\prime \prime}\right)$ pada pagi hari yaitu 1,184 $\mu \mathrm{g} / \mathrm{m}^{3}$. Hal tersebut dipengaruhi oleh adanya aktivitas-aktivitas tertentu yang mengharuskan manusia berpergian dengan menggunakan sumber bergerak (Kendaraan), sehingga terjadi kepadatan lalu lintas dimana apabila adanya kemacetan di Jalan tersebut maka akan terjadi proses pembakaran tidak sempurna pada setiap kendaraan yang menggunakan bensin dan akan menghasilkan Timbal $(\mathrm{Pb})$ yang akan tersebar secara merata serta bercampur pada area jalan lainnya, serta tingginya volume kendaraan yang menyebabkan tingginya kandungan kadar Timbal $(\mathrm{Pb})$ di bandingkan pada hari libur.

2. Jumlah Sumber Bergerak (Kendaraan) yang Lewat Pada Saat Pengukuran Di Jalan Mandai Kota Makassar.

Berdasarkan tabel 5.2 dari hasil pengukuran jumlah sumber bergerak (kendaraan) pada saat pengambilan sampel selama waktu 30 menit maka diperoleh hasil tertinggi pada pagi hari Di Titik I Di Jalan Dakota Maros-Makassar dengan Lokasi

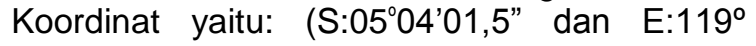
31'3,6") sebanyak 2980 unit dengan lama perhitungan selama 30 menit dan kandungan Timbal $(\mathrm{Pb})$ yang terdapat pada Titik I Di Jalan Dakota Maros-Makassar dengan Lokasi

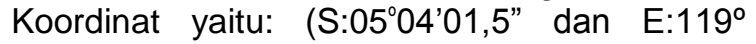
$31 ' 3,6$ ") pada pagi hari yaitu $1,184 \mu \mathrm{g} / \mathrm{m}^{3}$, sedangkan hasil terendah diperoleh pada sore hari Di Titik III Di Jalan Tol Insinyur Sutami dengan Lokasi Koordinat yaitu: (S: $05^{\circ} 04^{\prime} 05,4^{\prime \prime}$ dan E: 19³1'28,7") sebanyak 1776 unit.

Pada Titik II Di Jalan Bandara Baru Sultan Hasanuddin dengan Lokasi Koordinat yaitu: (S:0504'04,9",E: 119³1'32,2"), jumlah sumber bergerak (Kendaraan) Di Sekitar Jalan Bandara Baru Sultan Hasanuddin pada pagi hari dengan jumlah kendaraan sebanyak 2670 unit dengan lama perhitungan selama 30 menit dan kandungan Timbal (Pb) pada Titik II Jalan Bandara Baru Sultan Hasanuddin dengan 
Lokasi Koordinat yaitu: (S:0504'04,9", $\left.\mathrm{E}: 119^{\circ} 31^{\prime} 32,2^{\prime \prime}\right)$ pada pagi hari yaitu 0,562 $\mu \mathrm{g} / \mathrm{m}^{3}$.

Berdasarkan tabel 5.2 di atas diketahui bahwa hubungan kepadatan kendaraan dengan adanya kandungan Timbal $(\mathrm{Pb})$ pada pengukuran pada pagi hari menunjukkan bahwa semakin tinggi tingkat kepadatan kendaraan maka semakin tinggi pula tingkat kandungan Kadar Timbal (Pb) di udara. Asap kendaraan bermotor bisa mengeluarkan partikel $\mathrm{Pb}$ yang kemudian bisa mencemari udara,tanaman disekitar jalan raya,dan mencemari makanan yang dijajakan di pinggir jalan. Hal ini disebabkan karena pada saat pengukuran kandungan Timbal $(\mathrm{Pb})$ di udara juga dapat dipengaruhi oleh beberapa faktor yaitu pada saat pengukuran dapat dipengaruhi oleh arah dan kecepatan angin serta suhu dan kelembaban.

Pada Titik III Di Jalan Tol Insinyur Sutami dengan Lokasi Koordinat yaitu: (S:0504'05,4",E:19³1'28,7") jumlah sumber bergerak (Kendaraan) Di sekitar Jalan Tol Insinyur Sutami dengan Lokasi Koordinat yaitu: (S:050.'05,4",E:19³1'28,7') pada pagi hari dengan jumlah kendaraan sebanyak 2730 unit dengan kandungan Timbal $(\mathrm{Pb})$ yaitu 0,617 $\mu \mathrm{g} / \mathrm{m}^{3}$.

Berdasarkan tabel 5.3 diatas bahwa hubungan kepadatan kendaraan dengan adanya kandungan Timbal $(\mathrm{Pb})$ pada pengukuran pada pagi hari menunjukkan bahwa semakin tinggi tingkat kepadatan kendaraan maka semakin tinggi pula tingkat kandungan Kadar Timbal (Pb) di udara. Asap kendaraan bermotor bisa mengeluarkan partikel $\mathrm{Pb}$ yang kemudian bisa mencemari udara,tanaman disekitar jalan raya,dan mencemari makanan yang dijajakan di pinggir jalan. Hal ini disebabkan karena pada saat pengukuran kandungan Timbal $(\mathrm{Pb})$ di udara juga dapat dipengaruhi oleh beberapa faktor yaitu pada saat pengukuran dapat dipengaruhi oleh arah dan kecepatan angin serta suhu dan kelembaban.

Dari hasil perhitungan jumlah sumber bergerak (kendaraan) menunjukkan bahwa kepadatan kendaraan Di Jalan Dakota MarosMakassar pada Titik I Di Jalan Dakota MarosMakassar dengan Lokasi Koordinat yaitu: (S:0504'01,5”, E:119 31'3,6") pada waktu sore hari dengan jumlah kendaraan sebanyak 2840 unit dengan lama perhitungan selama 30 menit dan kandungan Timbal $(\mathrm{Pb})$ yang terdapat pada sore hari pada Titik I Di Jalan Dakota Maros-Makassar dengan Lokasi Koordinat

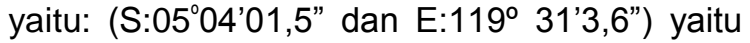
$0,782 \mu \mathrm{g} / \mathrm{m}^{3}$.

Pada Titik II Di Jalan Bandara Baru Sultan Hasanuddin dengan Lokasi Koordinat yaitu: (S:0504'04,9",E: 119³1'32,2”) pada waktu sore hari dengan jumlah perhitungan sumber bergerak (kendaraan) yang lewat pada saat pengukuran pada sore hari sebanyak 2563 unit dengan lama perhitungan selama 30 menit dan kandungan Timbal $(\mathrm{Pb})$ yaitu 0,635 $\mu \mathrm{g} / \mathrm{m}^{3}$.

Pada Titik III Di Jalan Tol Insinyur Sutami dengan Lokasi Koordinat yaitu: (S:050.'05,4",E:19³1'28,7') yang lewat pada saat pengukuran pada sore hari sebanyak 1776 unit. dengan kandungan Timbal $(\mathrm{Pb})$ yaitu $0,251 \mu \mathrm{g} / \mathrm{m}^{3}$.

Berdasarkan tabel 5.4 diatas bahwa hubungan kepadatan kendaraan dengan adanya kandungan Timbal $(\mathrm{Pb})$ pada pengukuran pada sore hari menunjukkan bahwa semakin tinggi tingkat kepadatan kendaraan maka semakin tinggi pula tingkat kandungan Timbal $(\mathrm{Pb})$ di udara. Hal ini disebabkan karena pada saat pengukuran kandungan Timbal $(\mathrm{Pb})$ di udara juga dapat dipengaruhi oleh beberapa faktor yaitu pada saat pengukuran dapat dipengaruhi oleh arah dan kecepatan angin,sinar matahari serta suhu dan kelembaban.

Peningkatan jumlah sumber bergerak (kendaraan) dinilai sebanding dengan peningkatan polutan yang ada di udara. Emisi gas buang

$\mathrm{NO}_{x}, \mathrm{SO}_{2}, \mathrm{CO}_{2}$, khususnya $\mathrm{CO}$ dan $\mathrm{Pb}$ pada pembakaran tidak sempurna dalam kendaraan bermotor sangat berbahaya bagi manusia. Polutan tersebut akan mencemari udara yang bersih,sehingga kebanyakan udara yang digunakan untuk bernapas justru udara yang tidak bersih serta banyak mengandung polutan. Hal ini disebabkan akan berdampak bagi kesehatan manusia yang bisa menimbulkan berbagai macam gangguan,khususnya gangguan pada saluran pernapasan (Budianto,2015).

Semakin bertambahnya jumlah sumber bergerak (Kendaraan) telah menimbulkan peningkatan pencemaran udara yang semakin pesat di kota-kota besar. Pembakaran bensin yang tidak sempurna dalam mesin kendaraan 
Jurnal Sulolipu : Media Komunikasi Sivitas Akademika dan Masyarakat

Vol. 17 No.II 2017

e-issn : 2622-6960, p-issn : 0854-624X

merupakan salah satu penyumbang terbesar polusi udara di kota. Polusi udara ini yang dikeluarkan bisa berupa Karbon Monoksida,Belerang Oksida,Nitrogen Oksida,dan partikel padatan seperti Timbal $(\mathrm{Pb})$. Senyawa ini dapat dijumpai dalam bahan bakar kendaraan dan minyak pelumas mesin. Pada rancangan mesin suatu kendaraan serta kualitas bensin ikut menentukan dalam jumlah pencemaran yang akan ditimbulkan. (Budianto 2015).

Banyaknya emisi gas buang yang di keluarkan pada sumber bergerak (Kendaraan) Di Jalan Mandai Kota Makassar sangat berpengaruh dengan adanya tingkat pencemaran udara pada Timbal $(\mathrm{Pb})$ dalam udara ambien

\section{KESIMPULAN DAN SARAN}

\section{Kesimpulan}

a. Ada pengaruh antara lokasi dan waktu pengukuran sumber bergerak (Kendaraan) dengan Kandungan Partikel Timbal $(\mathrm{Pb})$ pada pagi hari Di Jalan Simpang Lima Mandai Kota Makassar, hasil tertinggi yaitu pada pagi hari Di Titik I Di Jalan Dakota Maros-Makassar dengan Lokasi Koordinat yaitu: (S:0504'01,5",E:119 31'3,6") sebesar $1,184 \mu \mathrm{g} / \mathrm{m}^{3}$. Banyaknya emisi gas buang yang dikeluarkan pada sumber begerak (Kendaraan) sangat berpengaruh dengan adanya tingkat pencemaran udara pada Timbal $(\mathrm{Pb})$ dalam udara ambien, dan hasil tersebut masih memenuhi syarat sesuai dengan Lampiran Peraturan Gubernur Sulawesi Selatan Nomor 69 Tahun 2010 Tentang Baku Mutu Udara Ambien Dan Kriteria Kerusakan Lingkungan Hidup, untuk partikel Logam Berat Timbal $(\mathrm{Pb})$ dengan standar $2 \mu \mathrm{g} / \mathrm{m}^{3}$.

Kandungan Partikel Timbal $(\mathrm{Pb}) \mathrm{Di}$ Simpang Lima Mandai Kota Makassar berdasarkan Lokasi dan waktu pengukuran diperoleh hasil tertinggi yaitu pada pagi hari
Di Titik I Jalan Dakota Maros-Makassar dengan Lokasi Koordinat yaitu: (S:0504'01,5”, E:119 31'3,6”) dengan dua kali pengukuran yaitu sebesar $1,184 \mu \mathrm{g} / \mathrm{m}^{3}$, Hal ini di pengaruhi oleh adanya aktivitasaktivitas tertentu yang mengaharuskan manusia berpergian dengan menggunakan sumber bergerak (Kendaraan) sehingga terjadi kepadatan lalu lintas, dan hasil tersebut masih memenuhi syarat sesuai dengan Lampiran Peraturan Gubernur Sulawesi Selatan Nomor 69 Tahun 2010 Tentang Baku Mutu Udara Ambien Dan Kriteria Kerusakan Lingkungan Hidup, untuk partikel Logam Berat Timbal $(\mathrm{Pb})$ dengan standar $2 \mu \mathrm{g} / \mathrm{m}^{3}$.

b. Berdasarkan Lokasi dan Waktu Pengukuran Jumlah sumber bergerak (Kendaraan) yang lewat pada saat pengukuran Di Simpang Lima Mandai Kota Makassar diperoleh hasil tertinggi yaitu pada Titik I Di Jalan Dakota Maros-Makassar dengan Lokasi Koordinat

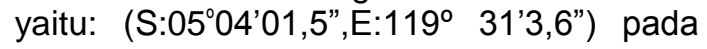
pagi hari dengan jumlah sumber bergerak (Kendaraan) sebanyak 2980 unit dengan lama waktu perhitungan selama 30 menit,hal ini dapat dipengaruhi bahwa semakin tinggi tingkat kepadatan kendaraan maka semakin tinggi pula tingkat kandungan Timbal $(\mathrm{Pb})$ di udara.

\section{Saran}

a. Disarankan agar peraturan yang ada mengenai pembatasan bensin bertimbal dan pembatasan penggunaan kendaraan yang sudah tua di terapkan.

b. Perlu adanya pemeriksaan secara berkala tentang kandungan logam berat Timbal $(\mathrm{Pb})$ pada saat uji coba pada kendaraan bermotor dan kendaraan roda empat.

c. Harus diterapkan kadar emisi bahan bakar kendaraan untuk mengurangi Kandungan logam berat Timbal $(\mathrm{Pb})$ di udara.

\section{DAFTAR PUSTAKA}

Anonim. 2010. Pencemaran Udara dari Sektor Transportasi (online) http://mathusen.wordpress. com/2010/01/24/ tentang Pencemaran-Udara- dari- Sektor- Transportasi.html diakses 10 Januari 2017.

Budianto, Ardi.2015. Bahaya Emisi Gas Buang Karbon Monoksida (CO) dan Timbal (Pb) Akibat Pembakaran Tidak Sempurna Kendaraan Bermotor Sebagai Polutan Udara, (Online), (ardibudianto.web.unej.ac.id,diakses 31 Mei 2017). 
Dinas Lingkungan Hidup Kota Makassar (ANDAL).2015. Volume dan Komposisi Lalu Lintas Kendaraan Bermotor pada ruas jalan Poros Bandara Baru. Pemerintah Kota Makassar: Makassar.

Dinas Perhubungan Kota Makassar, 2014. Data Jumlah Kendaraan Bermotor Kota Makassar. Pemerintah Kota Makassar: Makassar.

Darmono. 2001. Pengertian Logam Berat Timbal dan Dampak bagi Kesehatan. Jakarta: Universitas Indonesia.

Darmono. 2010. Lingkungan Hidup dan Pencemaran. Jakarta: Universitas Indonesia.

Dahlan, Rishar dkk.2013. Faktor Yang Berhubungan Dengan Kandungan Timbal (Pb) Dalam Udara Ambien di Wilayah Sekolah Dasar di Kawasan Pesisir Kota Makassar.(Online) (JURNAL. Pdf,diakses 31 Mei 2017).

Gusnita Desi. 2012. Pencemaran Logam Berat Timbal (Pb) Di Udara. Bandung. (Online) (JURNAL Lapan pdf.go.id,diakses 29 Mei 2017).

Isdaryati.2011. Gambaran Kandungan Logam Berat Timbal (Pb) Pada Udara Di Simpang Empat Jalan Daya Kota Makassar. Makassar Program Diploma III Jurusan Kesehatan Lingkungan Politeknik Kesehatan Makassar. (KTI tidak diterbitkan.)

Kantor Samsat Makassar. 2014. Data Kendaraan Bermotor yang telah direkapitulasi Kota Makassar (online),(http://www.pdpersi.co.id diakses 06 Januari 2017).

KPBB. 2004. Survei Kendaraan Masyarakat di Kota Besar Indonesia, (Online), (http://www.indonesianlic.org/papr, diakses 03 Januari 2017).

Mukono H.j.2003. Keadaan Cuaca Yang Mempengaruhi Suatu Kualitas Udara. Surabaya: Airlangga University Press.

Mukono H.j.2006. Efek Bahan Pencemar Udara. Surabaya: Airlangga University Press.

Nasution.2004. Efek Toksik Logam. Yogyakarta: Andi.

Republik Indonesia.2010. Perturan Gubernur Sulawesi Selatan No.69 Tahun 2010 Tentang Baku Mutu dan Kriteria Kerusakan Lingkungan Hidup.

Santi. 2001. Pencemaran Udara Oleh Timbal (Pb) Serta Penanggulangannya. Fakultas Kedokteran: Universitas Sumatera Utara.(Online),https://kesehatanlingkungankesmas.wordpress.com/2014/12/28/upaya-penurunantingkat-pencemaran-timbal-pb-di-perkotaan-menuju-green-city diakses 07 Januari 2017).

Samsia. 2011. Kadar Timbal (Pb) Di Traffic Light Jalan Hertasning Di Kota Makassar.Makassar: Politeknik Kesehatan Makassar.Jurusan Kesehatan Lingkungan.

Sudarmaji. 2006. Toksikologi Logam Berat B3 dan Dampaknya Terhadap Kesehatan. Bandung: Airlangga University Press.

Susilawaty, 2009. Analisis Kualitas Udara Ambient Kota Makassar. (Online),(http://www.uinalauddin.ac.id/download9.\%20A.\%20Susilawaty.pdf, diakses pada tanggal 15 Desember 2015).

Soedomo M.2001. Pencemaran Udara. Bandung: ITB. 
Jurnal Sulolipu : Media Komunikasi Sivitas Akademika dan Masyarakat

Vol. 17 No.II 2017

e-issn : 2622-6960, p-issn : 0854-624X

Supeno,Samson B.dkk. 2012, Penyehatan Udara. Makassar:Kementerian Kesehatan Republik Indonesia Politeknik Kesehatan Makassar.

Tribun. 2014 Jumlah Kendaraan di Indonesia. (online), (http://www.tribunnews.com/otomotif/2014/04/15/jumlah-kendaraan-di-indonesia-capai-104211 juta-unit, diakses pada tanggal 05 Desember 2017).

Techno. 2014 Pencanangan Pembangunan Underpass Maros,Makassar Di Simpang Mandai. (online),(http://www.technokonstruksi.com/techno-berita/63-pencanangan pembangunanunderpass-maros-makassar-di-simpang-mandai di akses pada tanggal 25 januari 2017).

Palar.H.2004. Pencemaran dan Toksikologi Logam Berat. Jakarta: Rineka Cipta.

Prabu.2008. Sumber Bahan Pencemar Udara terhadap Kesehatan. Jakarta: Anonimus.

Wardhana. Wisnu Arya. 2004.Dampak Pencemaran Lingkungan.Yogyakarta: Andi.

Widowati dkk.2008. Efek Toksik Logam.Yogyakarta: Andi. 